\title{
Analysis of Argument Strategies of Attack and Cooption: Stock Cases, Formalization, and Argument Reconstruction
}

\author{
ALAN BRINTON Boise State University
}

Key words: informal fallacy, stock case, formalization, argument reconstruction, principle of charity, ad verecundiam, ad hominem, ad populum, ad misericordiam, ad baculum.

Abstract: Three common strategies used by informal logicians are considered: (1) the appeal to standard cases, (2) the attempt to partially formalize so-called "informal fallacies," and (3) restatement of arguments in such a way as to make their logical character more perspicuous. All three strategies are found to be useful. Attention is drawn to several advantages of a "stock case" $^{\text {s" }}$ approach, a minimalist approach to formalization is recommended, and doubts are raised about the applicability, from a logical point of view, of a principle of charitable construal in the reconstruction of arguments.

\section{Introduction}

What I want to consider on this occasion is a kind of "formalist" approach to the so-called "fallacies" ad verecundiam, ad hominem, ad populum, ad misericordiam, and ad baculum.' By a formalist approach, what I mean is not an approach which reduces informal fallacies to formal ones, but an approach which begins from the hope that (a) for each of the argument types under consideration it is possible to specify a structure common to all instances, and that (b) the specified structure displays features which significantly distinguish the argument type from other argument types, features which are significantly relevant to evaluation of particular cases. Having special significance in relation to formalization in this sense are two other important ideas for informal logic, namely the use of stock cases and reconstruction of particular arguments.

\section{Stock Cases}

While formalization, the use of stock cases, and reconstruction are common practices in informal logic, in my opinion none of the three has been very clearly conceived. Let me begin with stock cases. My first thought was that a stock case would be one which has found its way into widely used introductory textbooks such as Copi's and Hurley's, which is repeated commonly in other texts and in theoretical discussions of informal fallacies, and which is generally regarded as an incontrovertible example of the argument type in question. Examples (1) and (2) come close to satisfying that description, though my expectation of finding them used repeatedly in other texts has been disappointed.

(1) But can you doubt that air has weight when you have the clear testimony of Aristotle affirming that all the elements have weight including air, and excepting only fire? $?^{2}$ 
(2) In that melancholy book The Future of an Illusion, Dr. Freud, himself one of the last great theorists of the European capitalist class, has stated with simple clarity the impossibility of religious belief for the educated man of today. ${ }^{3}$

But consider Hurley's more imaginative example:

(3) Pianist Ray Charles says that Sinclair paints are groovy. We can only conclude that Sinclair paints are very groovy indeed. ${ }^{4}$

(3) should also, in my opinion, be regarded as a stock case. Some cases that I would regard as stock - (1) and (2) for example-are in fact frequently repeated in the classroom. They, and others like them, are generally treated as exemplary and are commonly used in textbooks and in the classroom in introducing the idea of ad verecundiam argument, ad baculum argument, and so on. And such cases are typically interspersed among more controversial examples in exercise sets and on tests. The idea of a stock case is a useful one, partly because there is much wider (though not universal) agreement among textbook authors and informal logicians in a kind of ostensive defining of these argument types by reference to examples than there is among attempts at lexical or other kinds of definitions or in more discursive characterizations.

The fundamental thing about a stock case is its being generally acceptable as exemplary. All the better if it has a history, as does

(4) Hunters, accused of the barbaric slaughter of unoffending animals, sometimes reply by noting that their critics eat the flesh of harmless cattle.

which is used by Copi in explaining what an ad hominem is (Copi and Gould, 124). This example was introduced in Richard Whately's Elements of Logic (1826) as "a common instance" of ad hominem attack (III, 15n). Douglas Walton says that this case "has been cited so often in logic textbooks as a case of the circumstantial ad hominem fallacy that it can justifiably be called the classic example of the argument against the person." Walton, like a number of his predecessors, uses the hunters vs. carnivores ad hominem as a specimen in terms of whose analysis significant theoretical questions about this mode of argument can be addressed and resolved.

A second important feature of the stock case, then, is its suitability, since it is accepted as exemplary, as a specimen and as a test case for analysis and theoretical discussion. Now, while it has often been complained that many of what I am calling "stock cases" are artificial, their being generally acceptable as exemplary and as displaying the essential features of the supposed fallacy or mode of argument makes them fitting specimens for pedagogical and theoretical purposes. Without question, informal logicians need to pay serious attention to more complex and more realistic examples than, say, (3) above. But there is very good reason why an informal logician might devote close attention to simpler and even more artificial stock cases. To a great extent, we were all first introduced to the ideas of ad verecundiam argument, ad baculum, and so on primarily by having our attention drawn to stock textbook examples. My terminological 
suggestion is that we take "stock case" to mean a case which is suitable for these purposes.

There are some problems about stock cases, however. Two problems may be noted with regard to the kind of stock case we have in Copi's marvelous ad misericordiam

(5) Sir, surely I deserve a raise in pay. I can hardly manage to feed my children on what you have been paying me. And my youngest child must have an operation if he is ever to walk without crutches. (Copi and Cohen, 135)

One problem is that (5) is so stupid. The other (related) problem is that it is so conspicuously, and in a context-independent way, fallacious. Its being stupid is a problem because in real life hardly anyone would actually make such an inference. The speaker's personal troubles are too blatantly irrelevant to whether a pay increase is deserved. But, wait a minute . . ! People do indeed make such stupid inferences, as was observed long ago by the authors of the Port Royal Logic, who rightly represented common ways of moving from one proposition to another in terms of inferences such as "I didn't write this book; therefore it's a bad one" and "I love him; therefore he 's the cleverest person in the world." I have suggested elsewhere that one of the virtues of their attention to ludicrous inferences is that it exposes common modes of reasoning whose true character is often obscured, especially to reasoners themselves, and that exposing these modes of reasoning, laying them bare, and holding them up for ridicule is logically therapeutic. ${ }^{6}$ Stupid examples of common modes of fallacious inference also have the advantage of sticking with us as reminders of how not to think.

This brings us, though, to another problem with a stock case like (5), which lies in its obvious and relatively context-independent fallaciousness. Granting that (5) wouldn't have the advantages of holding logical stupidity up for ridicule unless it were fallacious, there is the attendant problem that regarding (5) as a stock case of ad misericordiam or (3) as a stock case of ad verecundiam suggests that the modes of argument are essentially fallacious, i.e. that "ad misericordiam," "ad verecundiam," and so on are best thought of as names for fallacies. My view is that it is much more advisable to treat them as modes of argument or argument strategies. Briefly, my reason is the desirability of separating the task of identification from that of evaluation and the undesirability of encouraging students to think that arguments can be fairly evaluated by the mere assigning of appropriate labels. For these and related reasons, I conclude that the fallaciousness of (3) and (5) should not be regarded as part of what makes them stock cases-although it may be useful to have in our inventory of stock cases some that are clearly fallacious, others that are clearly not, and yet others that are debatable. In other words, fallaciousness is not best regarded as part of the definition of argument ad hominem, etc. I also conclude that it is pedagogically unsound to focus attention exclusively or even heavily on logically stupid cases or even on other fallacious cases, regardless of their other virtues. 


\section{Formalization}

Some stock cases are more suggestive than others with regard to the possibility of meaningful structural representation. One of the earliest formalizers of arguments ad in the recent history of informal logic is Wesley Salmon, whose initial representation of the structure of argument from authority seems just about on target for (3) and close enough for (1):

(F.1)

$$
x \text { asserts that } p \text {. }
$$

Therefore, $p$. ?

It is a noteworthy fact about (2), on the other hand, that it, like many stock cases, is incomplete as an argument. Should there be anyone so dull as to be clueless about how to complete (2), though, (F.1) helps point in the direction of some such conclusion as that religious belief is nowadays unreasonable. And, in fact, this suggestiveness of standard forms could be a real and considerable advantage in more difficult cases. In other words, we may hope by means of assigning forms to modes of argument such as the ad verecundiam to gain one of the advantages of formal logic. To the extent that arguments ad verecundiam (or whatever) may be fairly represented as sharing some more detailed structure than is reported in mere " $p$; therefore $q$," a familiarity with that structure will provide a basis for identification and reconstruction of particular cases. And, although we won't expect evaluation of particular cases of these argument types to be reducible to mere examination of the structure (else we would be doing formal logic), we do have reason to hope they will be significant aids in the process of evaluation.

Fair structural representation of a mode of argument should not (in the case of arguments $a d$, at least) settle the question of general assessment of a mode of argument or the question of the evaluation of a particular case. The structural representation of any ad verecundiam, for example, should not make it automatically fallacious. For that reason, even though almost any argument having the form

(F.1')

There exists some $x$ or other who asserts that $p$.

Therefore, $p$.

will be a bad argument, that does not immediately rule out the possibility that (F.1) is the best general formalization of argument ad verecundiam. Everyone, whether he or she admits it or not, knows very well that there are reasonable appeals to authority. But, except possibly for some aberrant cases, appeals to authority are not deductive arguments, and it is not structural differences which distinguish reasonable appeals to authority from unreasonable ones. Something like (F.1) is common to every argument ad verecundiam. (F.1) does not represent everything that goes on in a logically healthy ad verecundiam; what else goes on is provided otherwise, in general by context, and in my opinion is not best represented as a matter of additional premises.

The premise regarding reliability which Salmon adds in his first refinement of (F.1) 
(F.1.1) $\quad x$ asserts that $p$.

$x$ is a reliable authority concerning $p$.

Therefore, $p$.

is not common to all, or perhaps even to most, actual arguments ad verecundiam; nor are the premises which he and others add to subsequent refinements. So I conclude that, despite the ingenuity and attractiveness of refinements in formalization proposed by Salmon and others, (F.1) should be regarded as the primary and theoretically superior formalization of argument ad verecundiam. This is not to deny the usefulness of more refined formalizations that draw attention to factors that are relevant to evaluation (such as reliability and subject matter). It might be argued, of course, that in every appeal to authority there are at least implications or presuppositions about expertise, reliability, appropriateness of subject matter, or whatever. I'm not sure this is true; but I grant that it is useful to ask what further conditions than are laid out in (F.1) have to be satisfied for an ad verecundiam to be a good one. I suggest, though, that the best pedagogical approach, at least from a pedagogical point of view, is to introduce just (F.1) as the structure of this mode of argument, to point out that the mere fact that $p$ is asserted does not provide grounds for its acceptance, and then to ask what the special conditions are which must prevail (which we could answer in terms of what other premises might be added) for $p$ 's having been asserted to give us good reason to conclude that $p$ is true.

Let me now turn in another direction in order to indicate that I am not too extreme of a minimalist. Consider Michael Wreen's formalization of the ad baculum. Professor Wreen claims that most ad baculums are expressed in a single statement having the form "If you (or he or she) doesn't ..., then " That by itself doesn't give us an argument structure, though, and we recognize that a meaningful structural representation of the ad baculum will have to involve the recognition that most actual cases are enthymematic. The Wreenean formalization, then, is something like

If you (or he or she) doesn't..., then

It would be very bad for you if

Therefore, you'd better....

Or, if we drop out the "or he or she" and give due recognition to the essentially dialectical character of the ad baculum, then we get

(F.2)

If you don't..., then I'll

It would be very bad for you if $I$ ed.

Therefore, you'd better....

Now, the situation is different here than with the ad verecundiam in what happens when we set out to formalize, and the difference is generally indicative of the fact that the ad baculum is more susceptible to formalization than the ad verecundiam. I think it is reasonable to believe that every adbaculizer is indeed committed to all that's represented by (F.2). The ad baculum is more susceptible to formalization in the sense that representation of structural features that are 
common to all, or all but a few aberrant ad baculums brings us much closer to the conditions that are relevant to whether the ad baculum is a good one or a bad one. In fact they reduce that question to a matter of the truth or falsehood of premiselike assertions to which the adbaculizer is committed.

Now consider the ad hominem. It, I maintain, is not nearly so susceptible as the ad verecundiam - to say nothing of the ad baculum - to formalization. A first thought, and one which might seem appropriate in the context of simple-minded treatments of ad hominem argument, is something like

$x$ asserts that $p$.

Therefore, $p$ is false.

But this certainly is not representative of the typical ad hominem, despite the fact that it does capture the form of some examples displayed in textbook treatments. Its inappropriateness as a representation of the ad hominem was recognized by Salmon, starting with the first (1963) edition of his Logic when he introduced

$x$ is a reliable anti-authority concerning $p$.

$x$ asserts that $p$.

Therefore, Not- $p$.

as representative of what he called "the argument against the man" as contrasted with the ad hominem. This distinction is terminologically infelicitous, but Salmon's comment that this is a departure from tradition "motivated by the symmetry between the argument from authority and the argument against the man ...." (Salmon 101n) points us in exactly the right direction-namely in the direction of the recognition that the ad verecundiam and the ad hominem are not symmetrical. This recognition is reinforced by the fact that the latter is more resistant to formalization than the former. This is because ad hominem argument is really about the person. Where $x$ is our opponent in argument, our ad hominems have as their conclusions assertions about $x$ in relation to $p$, while our ad verecundiams are about $p$ itself.

Possibly a case could be made for representing the ad hominem in terms of something like

$x$ has so-and-so characteristics.

Therefore, $x$ is not a credible asserter that $p$.

But (F.4) is not satisfactory, since the typical ad hominem has some more specific conclusion, such as that we shouldn't give weight to $x$ 's opinion on the present occasion, or that we shouldn't waste our time listening to $x$ 's arguments in favor of $p$, or that we shouldn't let $x$ play the role of advisor or take the lead in deliberations. What makes the ad hominem resistant to formalization is its variability with regard to possible kinds of conclusions. There is also the fact that ad hominems are often used when no particular $p$ is in question-although the conclusion often is best represented in relation to a particular $p$, on many occasions it is best represented in relation to a given context or problem or subject matter. So, although I would be glad to have someone prove otherwise, I do not 
believe that the ad hominem is as susceptible to formalization as the ad verecundiam. The same applies to arguments that we should give weight to someone's opinions, etc., for which

(F.4+) $\quad x$ has so-and-so characteristics.

Therefore, $x$ is a credible asserter that $p$.

is similarly inadequate as a representation. I would say that such arguments are positive ad hominems, just as the argument from anti-authority is a negative ad verecundiam. ${ }^{9}$

Now, when we come to the ad populum, matters are complicated by its supposedly having two forms. For one (sometimes called "the bandwagon"),

"Everybody" believes that $p$.

Therefore, $p$ is true.

seems like a reasonable possibility (though variations in the quantifier are a problem, and practice rather than belief is often what's at issue). It also suggests what some people already think, however, which is that this kind of so-called "ad populum" is really just a special case of the ad verecundiam. The other form of the ad populum ("appeal to the mob") is conceived as involving the arousing of strong (usually negative) emotions by means of various rhetorical devices. This other form is highly resistant to formalization.

Without wearing your patience thin by going into details about the ad misericordiam, I will just say that insofar as it is a matter of arousing emotions, it, like the ad populum, is pretty resistant to formalization. The arousing of emotions by means of discourse is a rhetorical phenomenon. It is susceptible to logical criticism insofar as emotions are more or less reasonable; but it is resistant to formalization.

Let me summarize some of my various loose thoughts about formalization. Formalizations, I suggest, are best derived from stock cases. Formalization is the first move toward theory. There are significant advantages to a relatively minimalist approach to formalization. Formalization of a mode of argument (in informal logic) should not be expected to fully reveal what is relevant to the general logical assessment of that mode of argument. It certainly should not beg the question of whether that mode of argument is in general fallacious. Formalization of a particular case should be expected to reveal some, but not all of what is relevant to the logical evaluation or criticism of that particular case. Some kinds of argument ad are more resistant to formalization than others; this draws attention to significant logical or other differences among these modes of argument, as is illustrated by the case of arguments ad verecundiam and ad hominem.

\section{Reconstruction}

Formalizations are useful devices in informal logic (as in formal), insofar as they are available, in the process of interpreting and reconstructing "real life" arguments. But there is much more involved in adequate argument reconstruction. 
In his article, "A Bolt of Fear," Michael Wreen suggests the following requirements for "proper" argument reconstruction:

(1) charitably interpreting and/or rewriting the argument, and perhaps even toning down or emending some of its claims;

(2) considering the argument in context, and if a relatively complete context isn't patent, imputing a plausible one;

(3) using all relevant background information;

(4) making standards of evidence explicit, or supplying likely ones;

(5) paying close attention to the content of the particular proposition being argued for, especially if it isn't explicitly stated..$^{10}$

These are useful suggestions. I suggest, though, a division of what Professor Wreen is talking about into three aspects:

(A) reconstruction, which would involve his (1) and (5), and which would be informed by

(B) contextualization, which includes (2) and (3) and would partly determine

(C) standards of evidence (or of appraisal).

I am inclined, then, to also take a relatively minimalist approach to reconstruction and to separate it from contextualization, as, I believe, Professor Wreen would separate it from standards of evidence. It is evaluation rather than reconstruction to which standards of evidence are directly relevant, except insofar as consideration of those standards informs charitable construal.

Speaking of charitable construal, it is noteworthy that a number of logic textbooks mention the so-called "Principle of Charity" in discussing argument interpretation. Johnson and Blair, for example, refer to it several times in their useful chapter "Interpreting Arguments", in their book Logical Self-Defense (New York: McGraw Hill, 1994); and it has been discussed in articles in Informal Logic, most notably in Ralph Johnson's "Charity Begins at Home" (Informal Logic Newsletter 3, no.3 (1981) 4-9), Johnson takes the basic formulation of the principle to be this:

(P.1) The Principle of Charity which governs all levels of argument analysis is that the critic should provide the best possible interpretation of the material under consideration. (5)

Professor Wreen practices a kind of charitable construal which I approve when he creates scenarios, as he does for stock cases of the ad baculum, in order to show that what appear to be fallacious ad baculums are not essentially and internally so. But as to the general application of a principle of charity in argument reconstruction I have serious doubts. The question is Why be charitable? Johnson says he agrees with Scriven that the justification for the principle is ethical. But what kind of a justification is that for a principle of argument interpretation? The Principle of Charity only makes sense if it can be depended upon to yield the most accurate readings of arguer's intentions. It's nice to be a nice guy, but our principles of interpretation or reconstruction should have epistemic justification. Rhetorically, it is often good strategy to credit one's 
opponents with stronger and more persuasive arguments than they really intend or are capable of (especially when an audience knows that this is what we're doing). But epistemically it does not make good sense. If people generally were good reasoners but poor communicators, the Principle of Charity would make sense. The most that can be said for it, though, is that being charitably inclined is a good corrective of the too common tendency toward uncharitable construal of opponents' arguments. But as a corrective to this unfortunate tendency Johnson's formulation of the Principle of Charity is much too strong. Wreen's requirement (1) is better. Better yet though less interesting would be a Principle of Impartiality, such as

(P.2) Be fair, be square, be unbiased and moderate in the interpretation of all material under consideration.

Unfortunately, impartiality seldom begins at home."

' What I have to say may also be suggestive with regard to some other kinds of arguments $a d$, such as arguments ad ignorantiam, and perhaps with regard to other of the so-called informal fallacies.

${ }^{2}$ Galileo Galilei, Dialogues Concerning Two New Sciences, as quoted in Irving Copi and Carl Cohen's Introduction to Logic, 9th edition (NY: Macmillan, 1994) 135.

${ }^{3}$ John Strachey, The Coming Struggle for Power, as quoted in Copi and Cohen, 133.

${ }^{4}$ Patrick Hurley, A Concise Introduction to Logic, 4th edition (Belmont, CA: Wadsworth, 1991) 137.

${ }^{5}$ Douglas N. Walton, Informal Logic: A Handbook for Critical Argumentation (Cambridge: Cambridge Univ, Pr., 1989) 145.

"See my "Seeing the World Through Our Own Eyes: The Doctrine of Logical Prejudices," Philosophy and Rhetoric 28 (1995). Compare Jean-Pierre de Crousaz, A New Treatise of the Art of Thinking (1724 translation of Systeme de Reflexions qui peuvent contribuer a la nettete et a l'entendue de nos connaissances, ou Nouvel Essai de Logique (Amsterdam: 1712)), Vol. II, 248 on Sophisms: "To see the Ridiculousness of them [logical influences of the passions], you need only form a Reasoning, where the Principle, on which the heart rests, is expressly declared. Marcarius is richer (r), therefore he reasons better." Also, Whately, Elements of Logic III.20: "There is indeed something laughable even in Fallacies which are intended for serious conviction, when they are thoroughly exposed."

'Wesley C. Salmon, Logic, 3rd ed. (Englewood Cliffs, NJ: Prentice-Hall, 1984) 98, as in the 1963 1st edition.

8 "A Bolt of Fear," Philosophy and Rhetoric 22 (1989) 138.

${ }^{9}$ I do believe that arguments from anti-authority are somewhat more common than Salmon suggests. It's just that they would not typically be cases best represented in terms of the truth or falsehood of some proposition. One kind of case would be where it is argued that so-andso's advising us to do such-and-such should count as a reason against doing such-and-such, since there are good reasons to think that so-and-so wants our enterprise to fail. 


\section{0 "A Bolt of Fear" 135.}

"Research for this essay was supported by a grant from the Idaho Humanities Council.

ALAN BRINTON DEPARTMENT OF PHILOSOPHY BOISE STATE UNIVERSITY BOISE, ID 83725 